\title{
Diagnosis by molecular pathology of an early and atypical histoplasmosis lesion in the duodenum of an immunocompromised patient: A case report
}

\author{
SAYOKO SUMIYOSHI ${ }^{1}$, SHINICHI TANAKA ${ }^{2}$, HIROTOMO KATO ${ }^{3}$, KOHJI TAKAGI $^{2}$, \\ TAKASHI MINAMISAKA ${ }^{2}$, AKIRA NOGUCHI ${ }^{2}$, TAKAHIKO NAKAJIMA ${ }^{2}$ and JOHJI IMURA ${ }^{2}$ \\ ${ }^{1}$ Medical Department, Faculty of Medicine, University of Toyama; ${ }^{2}$ Department of Diagnostic Pathology, \\ Field of Medical, Academic Assembly, University of Toyama, Toyama 930-0194; ${ }^{3}$ Division of Medical Zoology, \\ Department of Infection and Immunity, Jichi Medical University, Shimotsuke, Tochigi 329-0498, Japan
}

Received May 25, 2020; Accepted September 25, 2020

DOI: $10.3892 /$ br.2020.1382

\begin{abstract}
Histoplasmosis is a fungal infection caused by Histoplasma capsulatum (HC), which can occasionally be aggressive resulting in the formation of granulomatous lesions. These are usually located in the lungs; however, immunocompromised patients may occasionally develop disseminated lesions in other organs as well. Human immunodeficiency virus (HIV) primarily infects cells of the immune system expressing CD4 molecules. Not only does HIV multiply within these cells, but it can also kill them or otherwise cause loss of cellular function, leading to an immunocompromised state. As a result, in an immunocompromised patient, infection with HC can have serious implications, often the development of visceral histoplasmosis in different organs. Although several types of lesions are formed in $\mathrm{HC}$-infected organs, it may be difficult to distinguish the causative organism from other pathogens based on morphology alone. The present case report describes the case of a 57-year-old woman, from South America, who may have been infected with $\mathrm{HC}>20$ years previously, remaining asymptomatic over the years. She later developed a lesion in the duodenum associated with immunodeficiency caused by HIV infection. The differential diagnosis of this case was made on the basis of several specific morphological findings using histopathological analysis and molecular pathological techniques. The pathogenesis of characteristic lesions caused by $\mathrm{HC}$ in the presence of HIV infection was also reviewed.
\end{abstract}

Correspondence to: Dr Johji Imura, Department of Diagnostic Pathology, Field of Medical, Academic Assembly, University of Toyama, 2630 Sugitani, Toyama 930-0194, Japan

E-mail: imura@med.u-toyama.ac.jp

Abbreviations: HC, Histoplasma capsulatum; HIV, human immunodeficiency virus; GI, gastrointestinal tract; AIDS, acquired immunodeficiency syndrome

Key words: histoplasmosis, duodenum, histopathology, HIV, pathogenesis

\section{Introduction}

Histoplasmosis is a mycosis caused by Histoplasma capsulatum (HC) which can be aggressive under certain conditions. $\mathrm{HC}$ is a spore-forming, dimorphic fungus that has a hyphal morphology in the natural environment and a yeast-like morphology in the human host (1). HC is generally present in the soil, particularly in soil rich in bird and bat guano; the endemic region for histoplasmosis includes the Mississippi River basin of the United States and parts of South America $(2,3)$. Human-to-human transmission via a pulmonary route has not been reported, to the best of our knowledge (4). Only a few cases have been reported in Japan due to the rarity of $\mathrm{HC}$ in the natural environment (5). In Japan, the majority of the case reports are single cases only, and there are no publications summarizing the findings of these reports. HC infects the human lungs via the bronchi and clinical manifestations most often develop as pulmonary histoplasmosis. Several individuals have subclinical infections or exhibit mild, cold-like symptoms and heal spontaneously after 2-3 weeks (6). Infection with HC is characterized histopathologically by a granulomatous inflammation of the lung, with the fungal body being entrapped inside the granulomas in the lung (7). However, in immunosuppressed patients, such as those with acquired immunodeficiency syndrome (AIDS), organ transplant recipients and the elderly, the fungus may disseminate to other organs as visceral histoplasmosis (8). Sites of onset are diverse, including the skin, central nervous system and gastrointestinal (GI) tract. The development of lesions in the GI tract has been reported in several AIDS patients (9). The frequency of clinically diagnosed GI histoplasmosis is $3-12 \%$ of patients with disseminated histoplasmosis. GI lesions are found in $70 \%$ of disseminated histoplasmosis cases at autopsy (10). Rapid diagnosis and treatment are necessary as this infectious disease may be fatal. However, it can be difficult to diagnose accurately, due to a similarity in symptoms with bacterial and viral pneumonia, such as fever, chills, cough and shortness of breath, which can result in delayed treatment (11). There are several methods that facilitate diagnosis, including serological tests, culturing and morphological identification of 
fungal bodies by microscopy (8). HC must be differentiated from several other pathogens as the morphological findings may be inconclusive; thus, molecular techniques have been used to aid in identification. This molecular pathological methodology identifies specific DNA sequences from HC, potentially from very small amounts of specimen, and this method is the most effective approach for accurate diagnosis of HC infection (12).

The present report describes the case of a woman who was immunosuppressed due to an HIV infection, and a duodenal lesion was incidentally found by upper endoscopy. This report describes the diagnosis of the duodenal histoplasmosis lesion based on histopathological and molecular pathological studies.

\section{Case report}

Clinical presentation. The patient was a 57-year-old woman who was married from South America. She was originally healthy and had no relevant medical or family history. She had a persistent cough accompanied by sputum for several months; and thus visited the Toyama University Hospital where severe inflammatory findings in the upper nasopharynx were noted.

The physical findings on examination in the hospital were as follows: The patient's height was $153 \mathrm{~cm}$, weight $43 \mathrm{~kg}$, having lost $11 \mathrm{~kg}$ over the previous 4 months. She complained of general fatigue and nocturnal fever. Although occasionally troubled with constipation, she did not have consistent/prolonged complaints regarding gastrointestinal symptoms. Laboratory findings on admission showed that serum albumin levels were decreased $(3.2 \mathrm{~g} / \mathrm{dl})$, and $\gamma$-globulin levels $(34.7 \%)$, serum total protein levels $(8.6 \mathrm{~g} / \mathrm{dl})$ and CRP levels were increased $(0.75 \mathrm{mg} / \mathrm{dl})$. Peripheral blood counts indicated normocytic anemia (red blood cell count, $4.05 \times 10^{5} / \mu \mathrm{l}$; hemoglobin, $11.5 \mathrm{~g} / \mathrm{dl}$; hematocrit, $34.3 \%$ cells) with a leukocyte count of $39.8 \times 10^{3} / \mu 1$. Blood lymphocyte surface markers, CD4 and CD8, were assessed due to the persistent symptoms and potentially compromised immunity. The percentages of CD4 and CD8 T cells were as follows: $4.9 \% \mathrm{CD}^{+} \mathrm{CD}^{-}, 80.8 \% \mathrm{CD}^{-} \mathrm{CD}^{+}, 0.1 \% \mathrm{CD}^{+}{ }^{+} \mathrm{CD}^{+}$and $14.2 \%$ CD4-CD8 - The CD4:CD8 ratio was 0.1 , due to markedly decreased proportion of $\mathrm{CD}^{+} \mathrm{T}$ cells. An HIV antibody test was positive and a quantitative determination of HIV RNA yielded a value of $1.4 \times 10^{4}$ copies $/ \mathrm{ml}$. Thus, it was concluded that the patient was in an asymptomatic stage of AIDS, with consequent immunosuppression. Serological tests for cytomegalovirus and toxoplasma were negative and $\beta-D$ glucan was within the normal range. An upper endoscopy was performed and revealed a yellowish punctate and patchy lesion in the mucosa of the descending portion of the duodenum that was suspected to be lymphatic dilatation (Fig. 1). A plain chest radiograph showed no apparent changes in the lungs.

The patient was treated with clarithromycin and fluconazole, and re-examination by endoscopy and mucosal biopsy 2 months later revealed no abnormalities. There were no lesions in other organs. She was in a clinically latent state of AIDS with a low HIV viral load and was treated with a cocktail of anti-HIV drugs, including EVG/COBI/FTC/TAF for 5 months and a synthetic antibacterial for $>1$ year (still being administered).

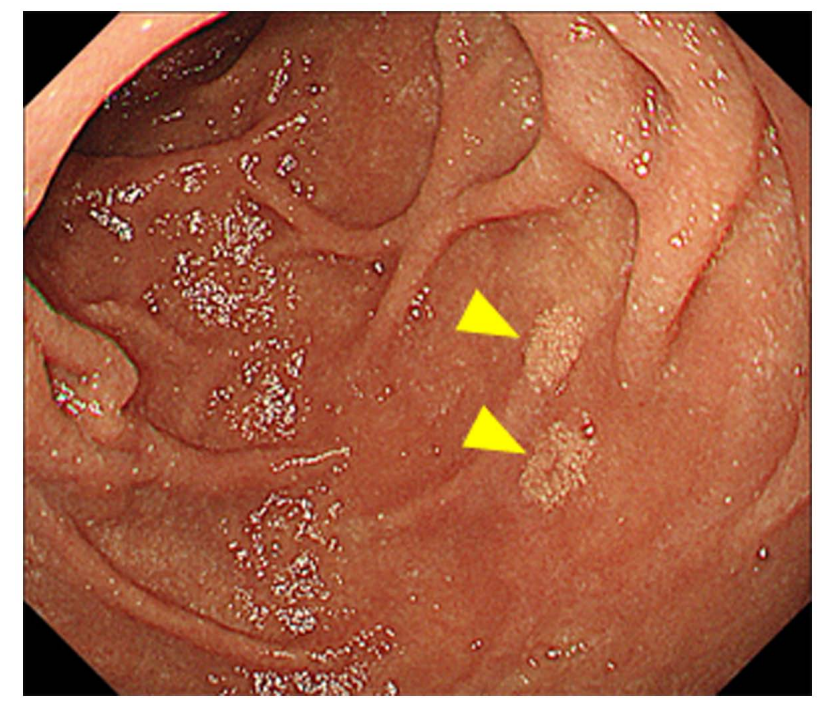

Figure 1. Endoscopic findings in the duodenum. The image shows a yellowish fine granular punctate and patchy lesions in the mucosa of the descending portion of the duodenum (arrow heads).

Pathological findings. All staining was performed at room temperature for $2 \mathrm{~h}$. An expanded lamina propria with numerous infiltrating foamy cells was observed in the hematoxylin and eosin (H\&E)-stained sections of the biopsy specimen from the duodenal mucosa. These foamy cells had several granular bodies with clear halos in the cytoplasm. Infiltration of the lamina propria by inflammatory cells other than the foamy cells was relatively rare, and most such cells were small lymphocytes. Granulomatous changes were not seen in the lamina propria. Structures suggestive of other infectious organisms were not found (Fig. 2A and B). Based on histopathological analysis, the granular bodies were stained positive with periodic acid-Schiff (PAS) (Fig. 2C). Using Grocott staining, these bodies were shown to possess a spherical or drop-like shape, 2-4 $\mu \mathrm{m}$ in diameter, and the central portion was slightly clear, showing a yeast-like form with no hyphae (Fig. 2D). Using immunohistochemistry, it was shown that the foamy cells were positive for CD68 and were confirmed to be histiocytes (Fig. 3A). In addition, the lymphoid cells infiltrating the lamina propria were primarily $\mathrm{CD}^{+}$cells, with very few $\mathrm{CD}^{+}$and $\mathrm{CD} 20^{+}$cells (Fig. 3B-D). Based on these findings, histopathologically, the duodenal mucosal lesion was initially considered to be a fungal infection with only a yeast-type morphology. HC was suspected as the most likely due to the characteristic morphological findings. This was consistent with the likelihood that cellular immunity in the patient's duodenal mucosa was compromised by the HIV infection.

Genetics analysis. Molecular pathological tests were performed to determine whether the fungal yeast-like particles in the foamy cells were HC. Genomic DNA was extracted from the paraffin sections of the duodenal mucosa using a QIAamp DNA FFPE Tissue kit according to the manufacturer's protocol (Qiagen, Inc.). PCR amplification was performed using universal primers for the fungal internal transcribed subunit (ITS) region. No product was amplified in the first PCR (Fig. 4A), but an additional run using the same primers 


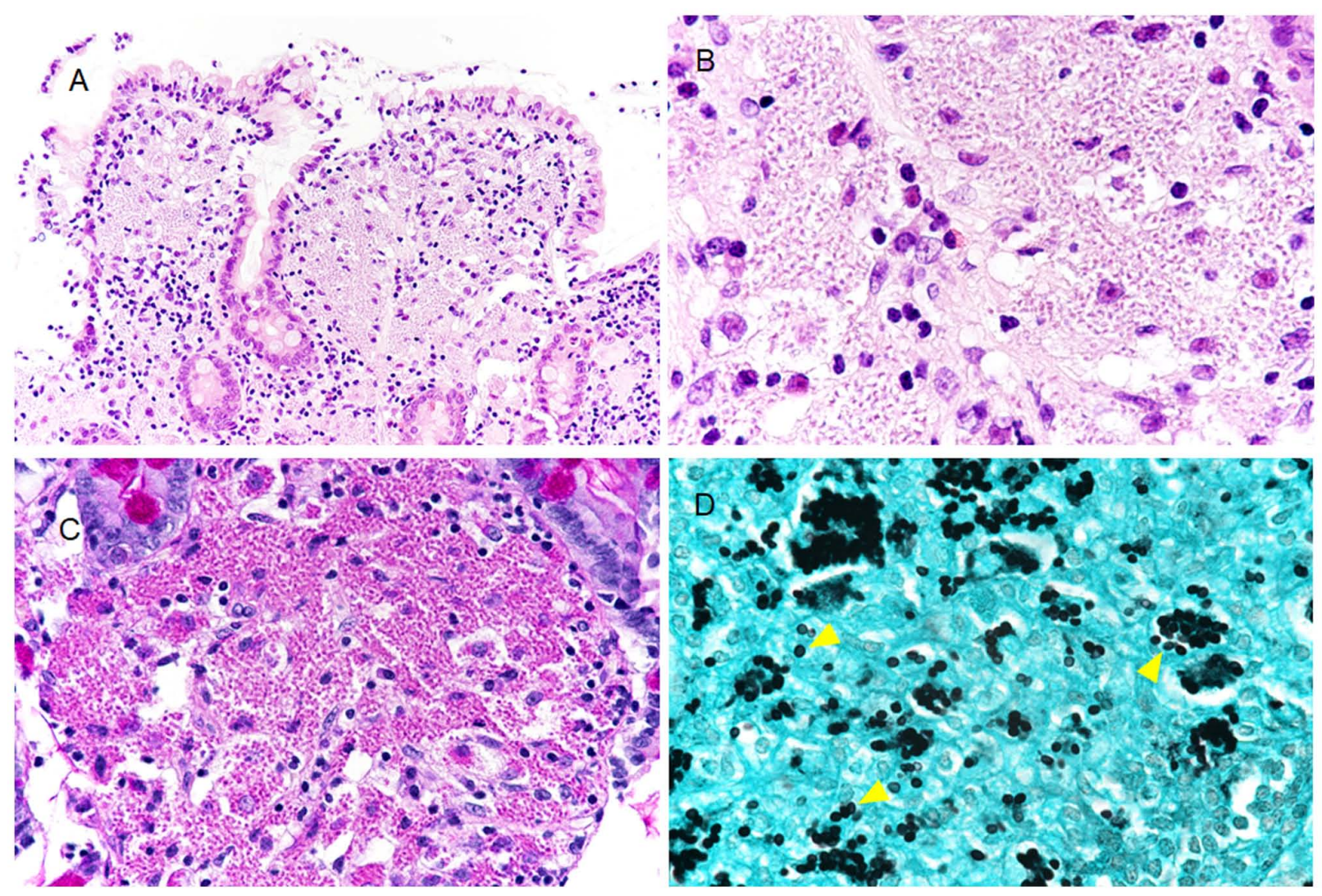

Figure 2. Histopathological findings in the duodenal mucosa based on hematoxylin and eosin staining. (A) Numerous foamy cells infiltrated the expanded lamina propria. Magnification, x10. (B) Several granular bodies with clear halos were present in the cytoplasm of the foamy cells. Magnification, x20. Based on histopathological analysis, the cytoplasmic granular bodies showed (C) a positive periodic acid-Schiff reaction (magnification, x20) and (D) Grocott staining (magnification, $\mathrm{x} 40$ ) as shown by the arrow heads.
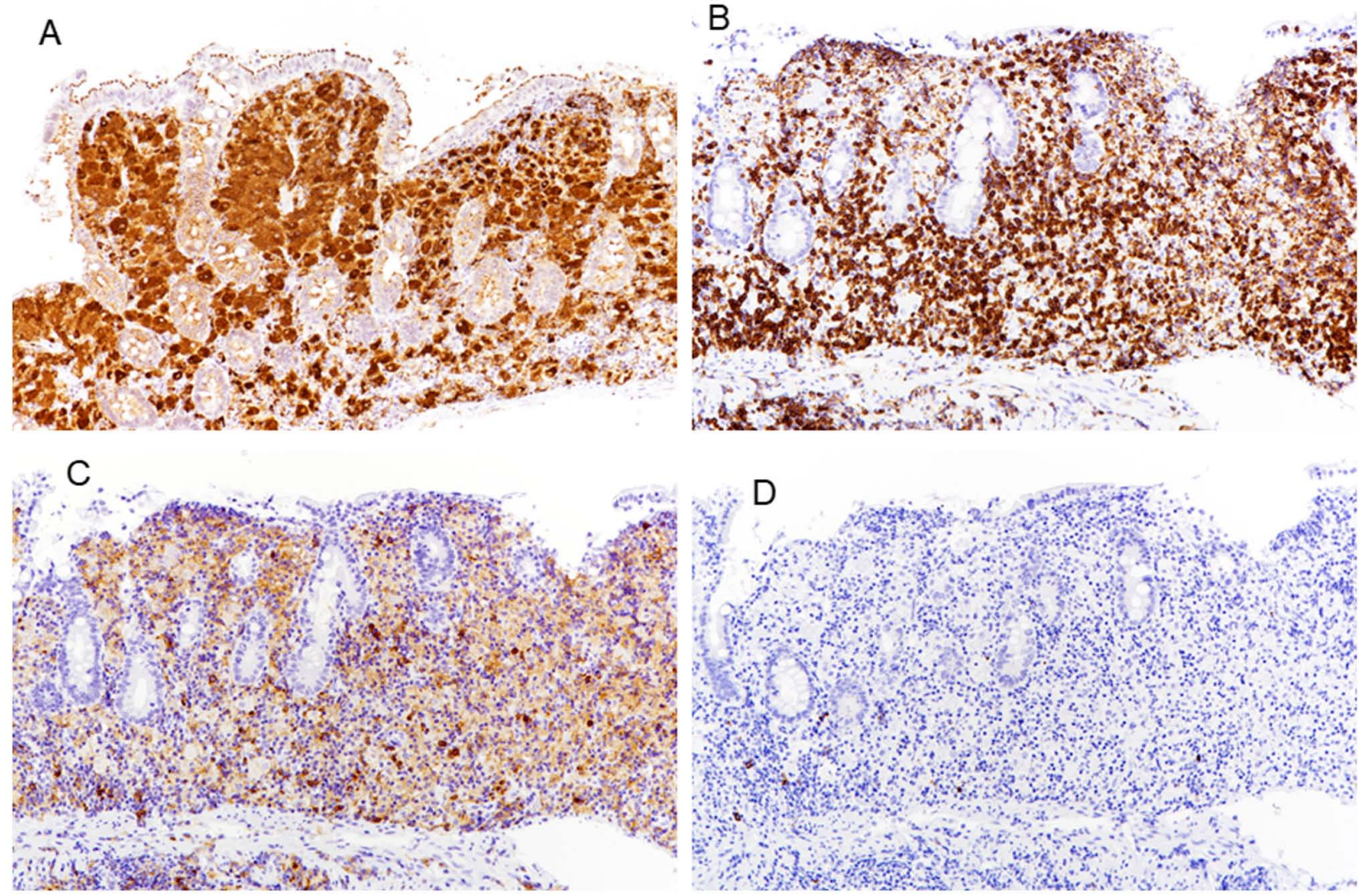

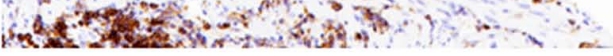

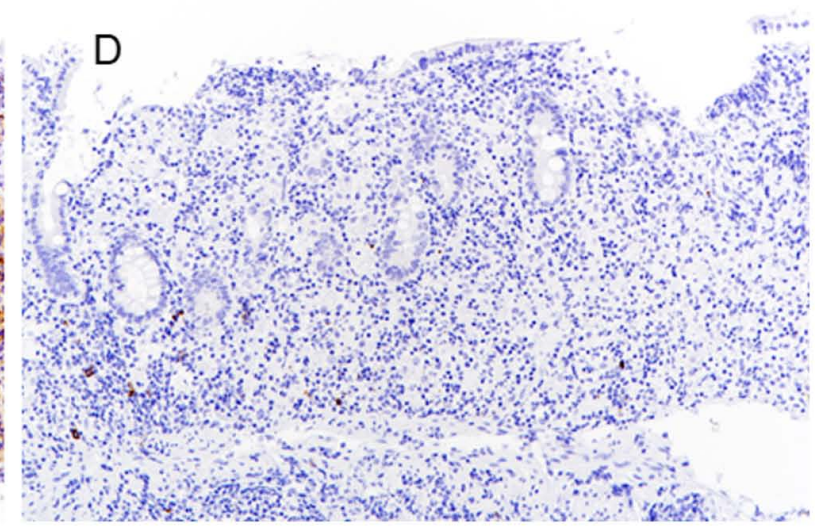

Figure 3. Histochemical findings. (A) Foamy cells were $\mathrm{CD} 68^{+}$. (B) $\mathrm{CD} 8^{+}$lymphocytes had mostly infiltrated into the lamina propria of the duodenal mucosa and only a few (C) $\mathrm{CD} 4^{+}$and (D) $\mathrm{CD} 20^{+}$lymphocytes were present. Magnification, $\mathrm{x} 10$. 

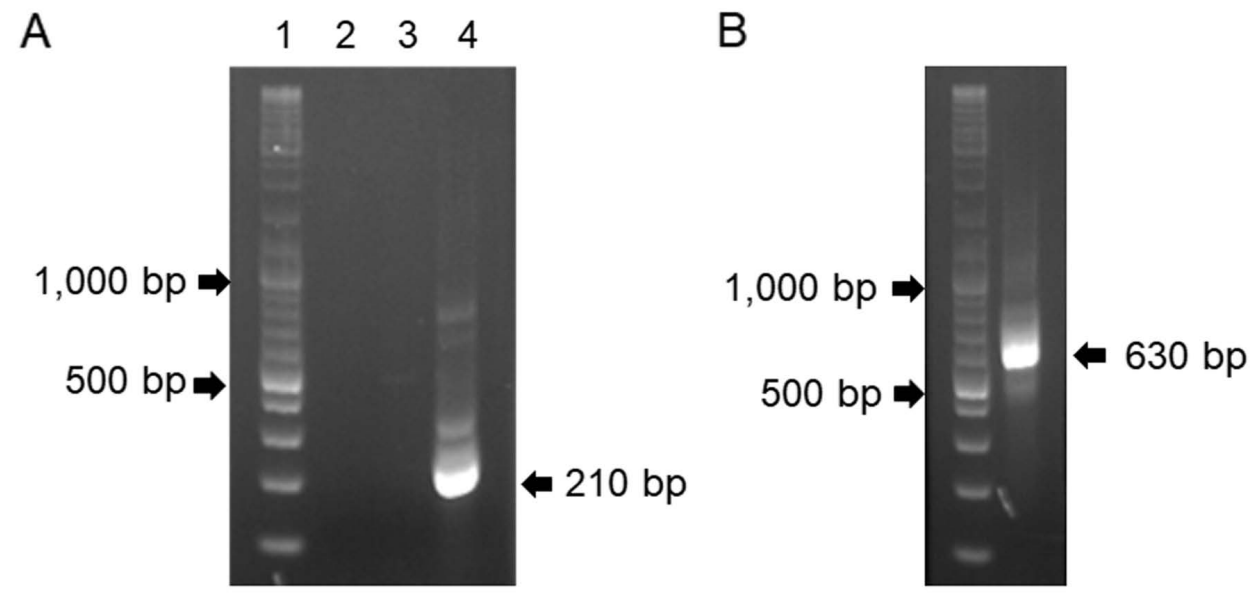

C

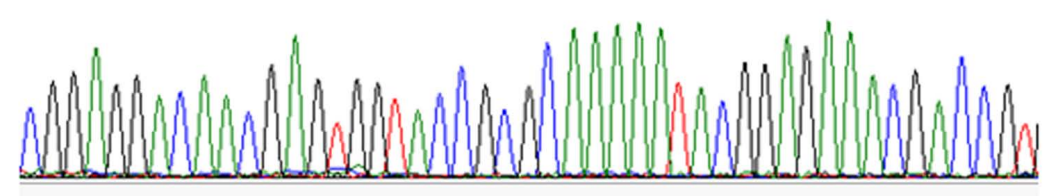

Figure 4. Results of PCR and direct sequencing. (A) Agarose gel electrophoresis: Lane 1, molecular size markers; Lane 2, the first PCR product from the ITS primers (ITS1 and ITS4); Lane 3, the product from the histoplasma first round (Hcl and HcII primers); and Lane 4, the product from the histoplasma second round (HcIII and HcIV primers). (B) Additional PCR product from the ITS region. (C) Analysis of the amplicon reveals sequences specific for HC (GenBank accession nos. LC523625 and LC517841). ITS, internal transcribed subunit; HC, Histoplasma capsulatum.

Table I. Primer sequences for the fungal ITS region and HC.

Sequence, $5^{\prime}-3^{\prime}$

ITS

$\begin{array}{ll}\text { Forward } & \text { TCCGTAGGTGAACCTGCGG } \\ \text { Reverse } & \text { TCCTCCGCTTATTGATATGC }\end{array}$

HC p100

HcI forward

GCGTTCCGAGCCTTCCACCTCAAC

HcII reverse

Inner primers

HcIII forward ATGTCCCATCGGGCGCCGTGTAGT

HcIV reverse

GAGATCTAGTCGCGGCCAGGTTCA AGGAGAGAACTGTATCGGTGGCTT

ITS, internal transcribed subunit; HC, Histoplasma capsulatum.

yielded an amplicon of $630 \mathrm{bp}$ (Fig. 4B). The product was cloned into the pGEM-T Easy vector (Promega Corporation) and subjected to nucleotide sequencing. In addition, a nested PCR specific for the HC p100 gene was performed using outer and inner primers. The PCR product was purified and the sequence was determined on both strands by direct sequencing (Sanger sequencing) with the inner primers, HcIII and HcIV. The sequences obtained (Fig. 4C) completely matched those of the HC ITS region and p100 gene registered in GenBank. The nucleotide sequence data generated are available in the
GenBank databases under the accession numbers LC523625 and LC517841. The sequences of the primers used are listed in Table I. The initial and nested PCR were performed using an AmpliTaq Gold 360 MasterMix (Thermo Fisher Scientific, Inc.) with the following thermocycling conditions: 30 cycles of denaturation at $95^{\circ} \mathrm{C}$ for $1 \mathrm{~min}$, annealing at $60^{\circ} \mathrm{C}$ for $1 \mathrm{~min}$ and extension at $72^{\circ} \mathrm{C}$ for $2 \mathrm{~min}$. From these results, the yeast-like particles found in the foamy cells of the duodenal mucosa were shown to be $\mathrm{HC}$.

\section{Discussion}

HC must be differentiated from other pathogens using morphological and molecular based approaches. These other pathogens include Candida glabrata, Cryptococcus neoformans, Talaromyces marneffei, Paracoccidioides brasiliensis, Sporothrix schenkii and Leishmania donovani, all of which are very similar to $\mathrm{HC}$ (13). $\mathrm{HC}$ is phagocytosed into the cytoplasm of macrophages, whereas the yeast cells of C. glabrata are rarely found within macrophages. $C$. neoformans has a capsule which may be stained using a polysaccharide stain. As $\mathrm{HC}$ is not encapsulated, these organisms cannot be observed using such staining methods; however, halos surrounding the fungi can be observed by microscopy (14). C. neoformans, when phagocytosed by macrophages, loses its capsule, and thus often appear small in size. In such a case, the fungal walls can be visualized by staining using the Fontana-Masson stain (15). T. marneffei may have a yeast-like form similar to that of HC, but a septum can be found in these oval-shaped yeast-like 
cells (13). P. brasiliensis is characterized by a mariner's wheel, which is formed by a mother cell surrounded by peripheral daughter yeasts $(16,17)$, and $S$. schenkii occasionally presents as an asteroid body (18). L. donovani is also similar to HC, but it is negative for the PAS reaction and Grocott staining (13). L. donovani is also characterized by its kinetoplast, an organelle which is not present in HC. Although the kinetoplast is difficult to detect by H\&E staining, it is possible to visualize using Giemsa staining (14). However, it is difficult to provide a diagnosis based on morphology alone as there are relatively few differences between these pathogens.

As detailed above, there are certain characteristic differential morphological findings which can be used to identify $\mathrm{HC}$, but definitive diagnosis is difficult in some cases. Thus, it may occasionally be necessary to base a diagnosis on the results of molecular techniques. The present case was unequivocally diagnosed by amplifying a specific genomic region of $\mathrm{HC}$ using nested PCR, followed by direct sequencing. The genomic DNA can be amplified and visualized readily, even from a small quantity of formalin-fixed, paraffin-embedded tissues, obtained from an endoscopic duodenal mucosal biopsy specimen. This is considered to be an extremely specific diagnostic method for differentiating $\mathrm{HC}$ from other pathogens, including other fungi.

The patient in the present report had not been abroad for 20 years and may already have been infected with $\mathrm{HC}$ when she came to Japan. Although she was in a clinically latent state of AIDS, it is likely that her immunocompromised condition led to the development of histoplasmosis. There are various considerations regarding the interrelationship between immunodeficiency caused by HIV infection and the development of histoplasmosis (19). HIV can infect not only $\mathrm{CD}^{+} \mathrm{T}$ cells but also $\mathrm{CD}^{+}$macrophages and dendritic cells. $\mathrm{CD}^{+} \mathrm{T}$ cells cannot differentiate following HIV, and a lack of $\mathrm{CD}^{+}{ }^{+} \mathrm{T}$ cell helper function underlies the deficiency of cytotoxic production in patients infected with HIV $(20,21)$. The phagocytic capacity of macrophages and the microbicidal ability of neutrophils are all impaired. $\mathrm{CD}^{+}$macrophages infected with HIV may be alive; however, their microbicidal activity is decreased (22). The number of $\mathrm{CD}^{+} \mathrm{T}$ cells was markedly reduced and a large number of macrophages phagocytosing $\mathrm{HC}$ were present in the duodenal mucosa of the patient. These findings support the hypothesis that macrophages are not destroyed by HIV infection but they may lose their ability to digest phagocytosed pathogens; accordingly, a large number of HCs would thus be present in the cytoplasm of these macrophages.

Histoplasmosis is characterized by the formation of granulomatous inflammatory lesions in the lung (5). However, no typical granulomatous changes were observed in the duodenal mucosa of this patient, and it is unclear why no granulomatous lesions were present there. One possible explanation is that the granuloma-forming activity of macrophages was decreased and differentiation into Th1 and Th17 cells from $\mathrm{CD}^{+} \mathrm{T}$ cells was impaired due to HIV infection $(23,24)$.

In conclusion, a case of histoplasmosis that occurred as the initial lesion in the duodenum of an HIV-infected patient is reported. It can be difficult to distinguish $\mathrm{HC}$ from other fungi and protozoa based on morphology alone. Therefore, the final diagnosis of duodenal histoplasmosis should be based on additional auxiliary techniques, including histopathological analysis and molecular pathological methods.

\section{Acknowledgements}

Not applicable.

\section{Funding}

No funding was received.

\section{Availability of data and materials}

The datasets used and/or analyzed in the present study are available from the corresponding author on reasonable request. The nucleotide sequence data generated are available in the GenBank databases under the accession numbers LC523625 and LC517841.

\section{Authors' contributions}

SS performed the experiments and wrote the manuscript. ST, KT, TM, AN, TN and JI contributed to the pathological analysis. HK performed the molecular analysis. JI designed the study and wrote the manuscript. All authors read and approved the final manuscript.

\section{Ethics approval and consent to participate}

Not applicable.

\section{Patient consent for publication}

Comprehensive consent was obtained from the individual participant for publication of this case report.

\section{Competing interests}

The authors declare that they have no competing interests.

\section{References}

1. Köhler JR, Hube B, Puccia R, Casadevall A and Perfect JR: Fungi that infect humans. Microbiol Spectr 5: FUNK-0014-2016, 2017.

2. Diaz JH: Environmental and wilderness-related risk factors for Histoplasmosis: More than bates in caves. Wilderness Environ Med 29: 531-540, 2018.

3. Bahr NC, Antinori S, Wheat LJ and Sarosi GA: Histoplasmosis infections worldwide: Thinking outside of the Ohio River valley. Curr Trop Med Rep 2: 70-80, 2015.

4. Deepe GS: Histoplasma capsulatum (Histoplasmosis). In: Mandell, Douglas, and Bennett's Principles and Practice of infectious diseases. Bennett JE, Dolin R and Blaser MJ (eds). 8th edition. Elsevier Saunders, Philadelphia, PA, pp2949-2962, 2014.

5. Hatakeyama S, Okamoto K, Ogura K, Sugita C and Nagi M: Histoplasmosis among HIV-infected patients in Japan: A case report and literature review. Jpn J Infect Dis 72: 330-333, 2019.

6. Kauffman CA: Histoplasmosis: A clinical and laboratory update. Clin Microbiol Rev 20: 115-132, 2007.

7. Mukhopadhyay S and Doxtader EE: Visibility of Histoplasma within histiocytes on hematoxylin and eosin distinguishes disseminated histoplasmosis from other forms of pulmonary histoplasmosis. Hum Pathol 44: 2346-2352, 2013.

8. Zanotti P, Chirico C, Gulletta M, Ardighieri L, Casari S, Roldan EQ, Izzo I, Pinsi G, Lorenzin G, Facchetti F, et al: Disseminated histoplasmosis as AIDS-presentation. Case report and comprehensive review of current literature. Mediterr J Hematol Infect Dis 10: e2018040, 2018. 
9. Sharma R, Lipi L, Gajendra S, Mohapatra I, Goel RK, Duggal R, Mishra SR and Gautam D: Gastrointestinal histoplasmosis: A case series. Int J Surg Pathol 25: 592-598, 2017.

10. Psarros G and Kauffman CA: Colonic histoplasmosis: A difficult diagnostic problem. Gastroenterol Hepatol (NY) 3: 461-463, 2007.

11. Azar MM, Loyd JL, Relich RF, Wheat LJ and Hage CA: Current concepts in the epidemiology, diagnosis, and management of histoplasmosis syndromes. Semin Respir Crit Care Med 41: 13-30, 2020.

12. Ohno H, Tanabe K, Umeyama T, Kaneko Y, Yamagoe S and Miyazaki Y: Application of nested PCR for diagnosis of histoplasmosis. J Infect Chemother 19: 999-1003, 2013.

13. Watanabe M, Hotchi M and Nagasaki M: An autopsy case of disseminated histoplasmosis probably due to infection from a renal allograft. Acta Pathol Jpn 38: 769-780, 1988.

14. Walsh TJ, Larone DH, Schell WA and Mitchell TG: Histoplasma, blastomyces, coccidioides and other dimorphic fungi causing systemic mycoses. In: Manual of Clinical Microbiology. Murray PR, Baron EJ, Jorgensen JH, Pfaller MA and Yolken RH (eds). Vol 2. 8th edition. ASM Press, Washington, DC, pp1781-1797, 2003.

15. Wojewoda C and Procop GW: Infections with Yeast and Yeastlike Fungi. In: Pathology of Infectious Diseases. Procop GW and Pritt BS (eds). Elsevier, Philadelphia, PA, pp531-572, 2014.

16. Schmitt BH and Pritt BS: Dematiaceous fungal infections. In Pathology of Infectious Diseases. Procop GW and Pritt BS (eds). Elsevier, Philadelphia, PA, pp516-530, 2014.
17. Headley SA, Pretto-Giordano LG, Di Santis GW, Gomes LA, Macagnan R, da Nobrega DF, Leite KM, de Alcantara BK, Itano EN, Alfieri AA, et al: Paracoccidioides brasiliensis-associated dermatitis and lymphadenitis in a dog. Mycopathologia 182: 425-434, 2017.

18. Zhang YQ, Xu XG, Zhang M, Jiang P, Zhou XY, Li ZZ and Zhang MF: Sporotrichosis: Clinical and histopathological manifestations. Am J Dermatopathol 33: 296-302, 2011.

19. Adenis AA, Aznar C and Couppie P: Histoplasmosis in HIV-infected patients: a review of new developments and remaining gaps. Curr Trop Med Rep 1: 119-128, 2014.

20. Abbas AK, Lichtman AH and Pillai S: Congenital and acquired immunodeficiencies. In: Cellular and Molecular Immunology. Abbas AK, Lichtman AH and Pillai S (eds). 9th edition. Elsevier, Philadelphia, PA, pp459-487, 2017.

21. Abbas AK, Lichtman AH and Pillai S: Immunity to microbes. In Cellular and Molecular Immunology. Abbas AK, Lichtman AH and Pillai S (eds). 9th edition. Elsevier, Philadelphia, PA, pp351-372, 2017.

22. Kumar V, Abbas AK and Aster JC: Diseases of the immune system. In: Robbins Basic Pathology. Kumar V, Abbas AK and Aster JC (eds). 10th edition. Elsevier, Philadelphia, pp121-188, 2017.

23. North RJ and Jung YJ: Immunity to tuberculosis. Annu Rev Immunol 22: 599-623, 2004.

24. Khader SA and Cooper AM: IL-23 and IL-17 in tuberculosis. Cytokine 41: 79-83, 2008.

This work is licensed under a Creative Commons Attribution-NonCommercial-NoDerivatives 4.0 International (CC BY-NC-ND 4.0) License. 